\title{
Directionality, prior experience, and left-right habits in paired-associate learning'
}

MARLENE A. SEGAL, UNIVERSITY OF TORONTO GEORGE MANDLER, UNIVERSITY OF CALIFORNIA, SAN DIEGO

Paired-associate lists were learned better unidirectionally (A-B on each Trial) than bidirectionally, where B-A had to be recalled on altemate trials. This difference did not appear on Trial 2, but once a pair was leamed in one direction, subsequent recall in the backward direction was lower than in the original direction. Left-right reading and coding habits affect PA learning. Prior experience apparently eliminates some of these differences.

In a previous paper (Segal \& Mandler, 1967), we have shown that traditional unidirectional paired-associate (PA) lists are learned somewhat more rapidly than bidirectional lists where A items (stimulus members) and $B$ items (response members) switch sides either systematically or unsystematically. The data also suggested that Ss identify membership of A item and B item sets by giving them "left side" and "right side" labels. The present study was designed to test the proposition that the superiority of unidirectional lists may be due to the presence of double cues, "stimulus" items, as well as position cues. Bidirectional and unidirectional lists will be examined with position cues either present or absent. In addition, the effect of prior PA learning on the acquisition of unidirectional and bidirectional lists will be examined.

\section{Method}

Forty-eight Ss were assigned to one of four groups. Each group first learned one PA list in Phase I and then a second list in Phase II. Both lists were learned under the same one of four PA conditions:

PA I-forward unidirectional; presentation: A (on stimulus side) for 2 sec., then A-B for 2 sec., with the same procedure used on all trials.

PA II-backward unidirectional; presentation: B (on response side of drum), A-B; on all trials.

PA III-bidirectional, constant cues; presentation: A (on stimulus side), A-B on trial $\underline{\text { n; }} B$ (on response side), A-B on trial $\underline{n+1}$.

PA IV-standard bidirectional; presentation: A, A$\mathrm{B}$ on trial $\underline{\mathrm{n}}$; $\mathrm{B}$ (on stimulus side), B-A on trial $\underline{n+1}$.

Sixty-four mono-and disyllabic words of AA frequency were selected from the Thorndike-Lorge tables. Two PA lists were constructed by random pairing. All Ss learned two lists, with half receiving List I first and half List II. Pairs were presented on a Stowe memory drum at 2:2 sec. rate. Ss were instructed that they were to learn 16 pairs of words, that they would be shown one member of the pair, which they were to read aloud and guess at the missing member, after which they would be presented with both members of the pair. After 12 trials they were given a five-minute rest and then presented the second list for twelve trials with similar instructions. Following the second list, Ss in the unidirectional conditions were given backward recall trials in which the B items (for PA I) and the A items (for PA II) were listed, and Ss were instructed to write in the missing items.

\section{Results}

Figure 1 shows learning curves for both phases of the experiment. In Phase I, PA III showed significantly poorer performance than the three other groups $(F=$ 4.66, $\mathrm{df}=1 / 40, \mathrm{p}<.05)$. The difference between the two unidirectional and the two bidirectional groups approached statistical significance $(F=3.78, \mathrm{df}=1 / 40$, $\mathrm{p}=.06)$. 'There are no significant differences in Phase II $(F<1)$, but the performance on Phase II is significantly better than in Phase I $(F=107.81, d f=1 / 40, p<.001)$. The Group by Phase interaction is also significant

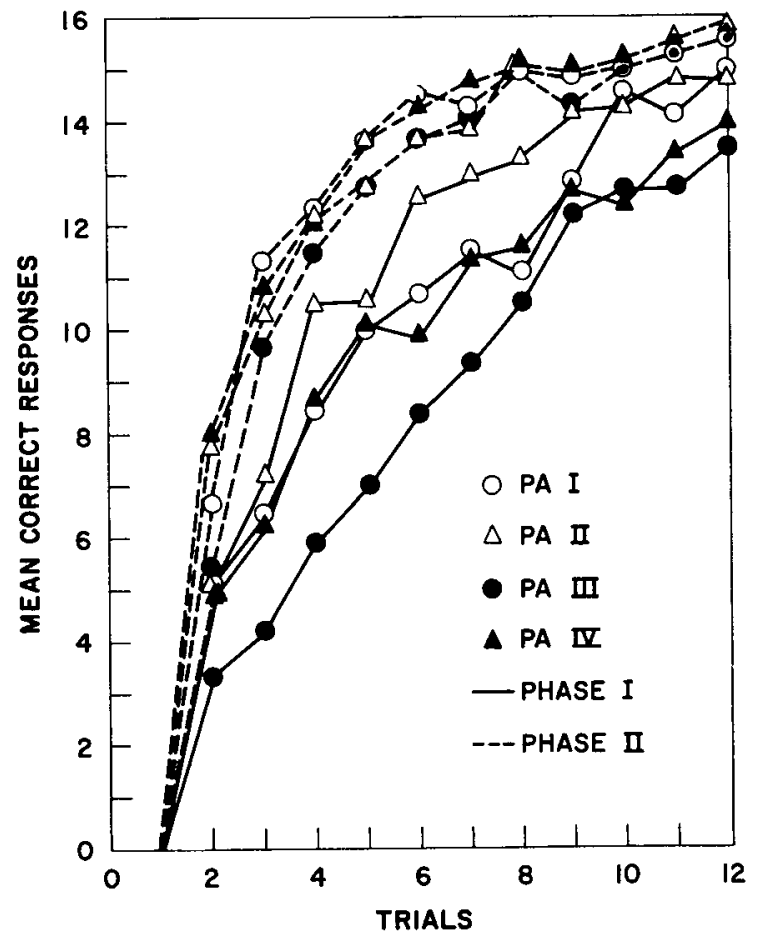

Fig. 1. Learning curves for four PA conditions in the two phases of the experiment. 
$(F=3.33, \mathrm{df}=3 / 40, \mathrm{p}<.05)$, suggesting that the bidirectional group profited more from prior experience than did the unidirectional groups. The probability of correct recall on Trial 2 showed the same pattern in both phases; the overall probabilities were $\mathrm{PAI}=.37, \mathrm{PAII}=$ .41 , PA III $=.27, \mathrm{PA}$ IV $=.41$. Only PA III is significantly different from the rest $(F=5.60, d f=1 / 88, p<.05)$. Probability of correct recall for each pair on Trial $\underline{n+1}$ was determined given that that pair was correctly anticipated for the first time on Trial $\underline{n}$. The data for the four groups combined for the two phases were: $\mathrm{PAI}=.78, \mathrm{PA} \mathrm{II}=.82, \mathrm{PA} \mathrm{III}=.65, \mathrm{PA}$ IV $=.73$. Only the difference between the two unidirectional (PA I and PA II) and the two bidirectional (PA III and PA IV) groups was significant $(F=13.52, \mathrm{df}=1 / 88, \mathrm{p}<.001)$. For the two unidirectional groups, the backward recall test following Phase II showed a significantly better performance for PA II (15.83 words) over PA I (15.18 words), $t=2.32, d f=22, p<.05$, though for both groups the mean is close to perfect performance (16.00). Discussion

There is a slight advantage for the unidirectional groups, but those pairs that are learned first, i.e., by Trial 2, show no advantage for the unidirectional groups in general, a result which replicates our previous data (Segal \& Mandler, 1967). Similarly, backward recall is almost perfect in Groups PA I and PA II in Phase II, i.e., after two lists have been learned in a single direction. Thus, associations acquired early, presumably with the most dominant mnemonics, and overlearned associations, do exhibit associative symmetry. On the other hand, once a pair is learned, recall on the next trial is more difficult if the directionality of the pair is reversed. This latter finding and the learning data in Phase I argue against associative symmetry (Asch \& Ebenholtz, 1962). At the same time, the data do not fully support the view that backward associations are examples of incidental learning (Feldman \& Underwood, 1957; Jantz \& Underwood, 1958). The latter view rests on associative strength as the explanatory vehicle. What is more likely is that the mnemonic devices used by Ss may at some times provide directionality and at others not. For example, the pair "Lamp-Chair" is better recalled in the unidirectional forward direction if the mnemonic is "The lamp is on the chair;" it will function bidirectionally if the mnemonic is categorical, e.g., "Things in a room."

One other consideration should be added to the directionality controversy, i.e., left-to-right reading, scanning and coding habits. The poor performance in PA III suggests that Ss might have great difficulty in switching from a "left to right" to a "right to left" recall set on every trial. Group PA IV made it possible for Ss to continue scanning from left to right, but original focusing had to be on the right side on every other trial for PA III.

Finally, the lack of significant differences in Phase II should be strongly underlined. Most of the differences and discussions mentioned above apply to naive Ss. Once Ss have had some experience with paired-associate learning, bidirectional coding apparently proceeds as quickly as unidirectional coding. Thus, human Ss can easily be reprogrammed through experience to apply new and more effective strategies to problems that are difficult for unprepared Ss. The attention to the effects of experience and instructions suggests new emphases in the study of human sophisticated, rather than naive, learning.

\section{References}

Asch, S. E., \& Ebenholtz, S. M. The principle of associative symmetry. Proc. Amer. Phil. Soc., 1962, 106, 135-163.

Feldman, S. M., \& Underwood, B. J. Stimulus recall following paired-associate learning. J. exp. Psychol., 1957, 53, 11-15.

Jantz, E. M., \& Underwood, B. J. R-S learning as a function of meaningfulness and degree of S-R learning. J. exp. Psychol., $1958,56,174-179$.

Segal, Marlene A., \& Mandler, G. Directionality and organizational processes in paired-associate learning. J. exp. Psychol., 1967, in press.

\section{Hoie}

1. Research reported here was supported by National Science Foundation Grants GB 810 and GB 5282. 